\title{
Influência do Processo Inflamatório na Concentração Sérica de Ferro de Pacientes em Hemodiálise
}

\author{
The influence of the inflammatory process on serum iron $\mathrm{c}$ \\ oncentration in hemodialysis patients
}

\author{
EDUARDO OTTOBELLI CHIELLE ${ }^{1}$ \\ JANICE RIGO ${ }^{2}$
}

\section{RESUMO}

Introdução: A insuficiência renal é caracterizada pela diminuição da função renal e quando instalada é necessário realizar tratamento de substituição renal a longo prazo através da hemodiálise. Frequentemente pacientes em tratamento hemodialítico apresentam inflamação aguda ou crônica, podendo haver alterações em marcadores inflamatórios como ferritina que por sua vez pode modificar parâmetros relacionados ao metabolismo do ferro. Material e Métodos: Foi realizado um estudo transversal com 46 pacientes com doença renal crônica, em hemodiálise, de ambos os sexos, provenientes da Clínica Renal do Extremo Oeste Catarinense. As amostras de sangue foram coletadas antes das sessões de hemodiálise e posteriormente foram mensuradas as concentrações séricas de ureia, creatinina, PCR-us, ferro e ferritina. Resultados: Observou-se aumento dos marcadores renais creatinina $(8.8 \mathrm{mg} / \mathrm{dL}$ para homens e $8.5 \mathrm{mg} / \mathrm{dL}$ para mulheres) e ureia (191 mg/dL para homens e $165 \mathrm{mg} / \mathrm{dL}$ para mulheres) e, sem diferenças significativas entre homens e mulheres $(p=0,56)$. Os resultados mostraram uma concentração sérica de ferro ( $57.6 \mathrm{mg} / \mathrm{dL})$, ferritina $(412 \mathrm{mg} / \mathrm{dL})$ e PCR-us $(6.8 \mathrm{mg} / \mathrm{dL})$ maior nos homens, sendo que somente as mulheres apresentaram níveis de ferritina $(376 \mathrm{mg} / \mathrm{dL}$ ) superiores aos valores de referência recomendados. Foi encontrado uma correlação positiva e significativa entre PCR-us e ferritina ( $p=0,001, r=0.4474)$ e uma correlação negativa entre ferro e PCR-us, ( $p=-0,04, r-0.3003)$. Conclusão: Observou-se que pacientes com Doença Renal Crônica e em hemodiálise apresentam marcadores inflamatórios significativamente aumentados quando comparados aos valores de referências recomendados. As proteínas de fase aguda em especial a ferritina, podem interferir sobre a concentração sérica do ferro, promovendo um déficit funcional deste composto o que pode contribuir para o desenvolvimento de anemias neste grupo de pacientes.

\section{DESCRITORES}

Ferritina. Hemodiálise. Insuficiência Renal. Inflamação.

\begin{abstract}
Introduction: Renal insufficiency is characterized by decreased renal function whose treatment consists of long-term renal replacement therapy by hemodialysis. Patients undergoing hemodialysis commonly present acute or chronic inflammation, which may change some inflammatory markers, including ferritin. As a result, these changes may modify parameters related to iron metabolism. Material and Methods: This was a cross-sectional study including 46 patients of both sexes with chronic renal disease undergoing hemodialysis. The subjects were selected from the Clínica Renal do Extremo Oeste Catarinense. Blood samples were collected before hemodialysis sessions and subsequently measured for serum concentrations of urea, creatinine, CRP, iron and ferritin. Results: There was an increase in the renal markers for creatinine $(8.8 \mathrm{mg} / \mathrm{dL}$ for men and $8.5 \mathrm{mg} /$ $\mathrm{dL}$ for women) and urea (191 mg / dL for men and $165 \mathrm{mg} / \mathrm{dL}$ for women), with no significant differences between men and women ( $p=$ $0.56)$. The results showed concentrations of serum iron $(57.6 \mathrm{mg} /$ $\mathrm{dL})$, ferritin (412 $\mathrm{mg} / \mathrm{dL}$ ) and CRP (6.8 mg / dL) higher in men, and only women had ferritin levels $(376 \mathrm{mg} / \mathrm{dL}$ ) above the recommended reference values. A positive and significant correlation between CRP and ferritin was found $(p=0.001, r=0.4474)$ as well as a negative correlation between iron and $\operatorname{CRP}(p=-0.04, r-0.3003)$. Conclusion: Patients with chronic renal disease undergoing hemodialysis had significantly increased inflammatory markers when compared to the recommended reference values. Acute-phase proteins, in particular ferritin, can interfere with the serum iron concentration providing a functional deficit of this compound, which can contribute to the development of anemia in these patients.
\end{abstract}

\section{DESCRIPTORS}

Ferritin. Hemodialysis. kidney failure. Inflammation.

Professor do Departamento de Ciências da Vida - Laboratório de Bioquímica Clínica da Universidade do Oeste de Santa Catarina (UNOESC), São Miguel do Oeste - SC.

2 Acadêmica do curso de Biomedicina da Universidade do Oeste de Santa Catarina (UNOESC), São Miguel do Oeste - SC. 
$\mathrm{A}$ insuficiência renal caracteriza-se pela diminuição da função renal, sendo atualmente um problema de saúde pública mundial. Esta enfermidade pode ter uma evolução rápida ou lenta, apresenta elevadas taxas de morbidade e mortalidade e acarreta um impacto negativo sobre a qualidade de vida dos pacientes acometidos. Existe no mundo cerca de 1,2 milhão de pessoas que se encontram sob tratamento dialítico $^{1}$, sendo que, no Brasil, este número alcança cerca de 97.586 indivíduos, desse total 57,7\% são do sexo masculino e $42,3 \%$ do sexo feminino ${ }^{2}$.

No decorrer dos últimos anos houve um aumento significativo nas internações e tratamentos decorrentes de complicações renais, que resultaram consequentemente no aumento de pacientes sujeitos a hemodiálise, como única forma de manter a vida ${ }^{3}$.

Quando comprovada lesão renal, é necessário fazer um tratamento de substituição renal em longo prazo, o qual é feito através da hemodiálise que permite a retirada de metabolitos tóxicos acumulados no sangue, como ureia, creatinina, ácido úrico, entre outras substâncias que estão em excesso no organismo ${ }^{4}$. Frequentemente pacientes em tratamento dialítico apresentam inflamação aguda ou crônica. As causas para a resposta inflamatória exacerbada na doença renal nestes pacientes ainda não estão bem esclarecidas. Existem, no entanto, várias fontes possíveis como a presença de bactérias ou a ocorrência de biofilme na superfície interna dos condutos de sangue, incompatibilidade com a membrana do dialisador e infecção do acesso vascular ${ }^{5}$.

Além disso, a doença renal crônica é considerada uma das patologias que induz a liberação de citoquinas pró-inflamatórias. Estas citoquinas estão associadas ao aumento de proteínas de fase aguda como a Proteína C Reativa e ferritina (PCR $)^{5}$. A PCR é uma proteína de fase aguda que está aumentada em casos de inflamação e ou infecção, é sintetizada nas células hepáticas por influência de citocinas pró-inflamatórias, particularmente a interleucina- 6 e interleucina- 1 e fator de necrose tumoral-alfa ${ }^{6}$

A ferritina é uma proteína encontrada em todas as células, especialmente nas envolvidas na síntese de compostos férricos e no metabolis-mo e reserva do ferro. Sua concentração aumenta em resposta a infecções, traumatismos e inflamações agudas. A sua elevação ocorre nas 24 a 48 horas iniciais, com um pico no terceiro dia, e se mantém elevada por algumas semanas $^{7}$. Nos processos inflamatórios a ferritina interfere no mecanismo de ação da Eritropoietina e consequentemente no metabolismo do ferro e aumenta paralelamente as citocinas pré-inflamatórias como a interleucina- $6^{5}$.

Desse modo, o objetivo deste estudo foi avaliar as concentrações de ferro e ferritina e verificar sua relação com o processo inflamatório em pacientes submetidos à hemodiálise, visto que, estes biomarcadores podem ser úteis no diagnóstico e acompanhamento das alterações no metabolismo do ferro em pacientes com processo inflamatório e submetidos a diálise.

\section{MATERIAIS E MÉTODOS}

\section{População de Estudo}

Foi realizado um estudo transversal com 46 pacientes com doença renal crônica, em hemodiálise proveniente da Clínica Renal do Extremo Oeste Catarinense de São Miguel do Oeste - SC. O protocolo de estudo foi aprovado pelo Comitê de Ética e Pesquisa com Seres Humanos da Universidade do Oeste de Santa Catarina sob o número 449.917. O estudo incluiu 21 mulheres e 25 homens numa faixa etária entre 18 e 90 anos. A média de tempo das sessões de hemodiálise foi de 3 a 4 horas, 3 a 4 vezes por semana, com fluxo de sangue superior a $250 \mathrm{~mL} / \mathrm{min}$, fluxo de dialisado 500 $\mathrm{mL} / \mathrm{min}$ e tampão de bicarbonato. As principais causas de insuficiência renal crônica foram nefroesclerose hipertensiva, glomerulonefrite crônica, nefroesclerose diabética, doença renal policística e outras doenças ou causa desconhecida.

\section{Análises Laboratoriais}

A coleta foi realizada na própria Clínica Renal do Extremo Oeste Catarinense, após a explicação da pesquisa e a assinatura do Termo de Consentimento Livre e Esclarecido. As amostras de sangue foram coletadas antes das sessões de hemodiálise. As amostras foram colocadas em tubo com gel separador o qual foi centrifugado por $20 \mathrm{~min}$ a $4000 \mathrm{rpm}$ e o soro foi separado e armazenado a $-20^{\circ} \mathrm{C}$ para análises posteriores. As dosagens de ureia, creatinina e ferro 
foram determinadas em amostras de soro, conforme técnicas estabelecidas pelo fabricante (LABTEST Diagnóstica SA, MG, Brasil), e os resultados foram expressos em mg/dL. A dosagem da ferritina foi determinada em amostras de soro conforme técnicas estabelecidas pelo fabricante (ROCHE Diagnostics GMBH, D-68298 Mannheim, Alemanha) no aparelho Elecsys 2010 com a metodologia de Eletroquiolumiescência os resultados foram expressos em $\mathrm{ng} /$ $\mathrm{mL}$. As dosagens de PCR-us foram determinadas em amostras de soro, conforme técnicas estabelecidas pelo fabricante (Biotécnica Diagnóstica MG, Brasil) com a metodologia de turbidimetria em aparelho automatizado, Cobas Mira Plus sendo os resultados expressos em mg/ dL.

\section{Análise dos Dados}

Os resultados foram expressos em média $\pm \mathrm{DP}$. Os dados foram analisados estatisticamente com o auxílio do programa SPSS (Statistical Package for the Social Sciences) 17.0 (Chicago, EUA). A normalidade dos resultados foi verificada pelo teste KolmogorovSmirnov. A diferença entre as médias foram avaliadas pelo testes t-Student para dados paramétricos e o teste Mann-Whitney para dados não paramétricos, considerando significativos os resultados $\operatorname{com} p<0,05$.

\section{RESULTADOS}

Foram analisados um total de 46 amostras de pacientes em hemodiálise, sendo que desses 25 pacientes eram do sexo masculino com faixa etária de 29 e 90 anos e 21 do sexo feminino com idade entre 18 e 80 anos. Os resultados encontrados são expressos na Tabela 1. Não foram observadas diferenças significativas entre os gêneros.

Observou-se uma correlação positiva e significativa entre as determinações de PCR-us e ferritina ( $p=0,001, r=0.4474$ ), Figura 1. Observou-se também uma correlação significativamente negativa entre os valores de ferro e PCR-us, $(p=-0,04, r=-0.3003)$ como ser observado na figura 2 .

\begin{tabular}{|c|c|c|c|c|c|c|}
\hline & $\begin{array}{c}\text { Amostra } \\
\text { Total }\end{array}$ & Homens & Mulheres & $p$ & $\begin{array}{c}V R \\
\text { HOMENS }\end{array}$ & $\begin{array}{c}V R \\
\text { MULHER } \\
\text { ES }\end{array}$ \\
\hline $\mathbf{N}$ & 46 & 25 & 21 & & & \\
\hline Idade & $61 \pm 17$ & $66 \pm 15$ & $57 \pm 19$ & 0.56 & & \\
\hline $\begin{array}{c}\text { Creatinina } \\
(\mathrm{mg} / \mathrm{dL})\end{array}$ & $8.6 \pm 3.2$ & $8.8 \pm 3.5$ & $8.5 \pm 2.9$ & 0.65 & $0,7-1,2$ & $0,5-1,0$ \\
\hline $\begin{array}{c}\text { Ureia } \\
(\mathrm{mg} / \mathrm{dL})\end{array}$ & $177 \pm 75$ & $191 \pm 82$ & $165 \pm 68$ & 0.40 & $15-45$ & $15-45$ \\
\hline $\begin{array}{c}\text { Ferro } \\
(\mathrm{mg} / \mathrm{dL})\end{array}$ & $55.2 \pm 20.3$ & $57.6 \pm 18.4$ & $49.3 \pm 22.5$ & 0.29 & $65-170$ & $50-170$ \\
\hline $\begin{array}{c}\text { Ferritina } \\
(\text { ng/dL) }\end{array}$ & $\begin{array}{c}337(227- \\
588)\end{array}$ & $\begin{array}{c}412(158- \\
537)\end{array}$ & $\begin{array}{c}376(282- \\
669)\end{array}$ & 0.07 & $30-400$ & $13-150$ \\
\hline $\begin{array}{c}\text { PCR-us } \\
(\mathrm{mg} / \mathrm{L})\end{array}$ & $\begin{array}{c}6.3(4.2- \\
25.3)\end{array}$ & $\begin{array}{c}6.8(3.7- \\
22.4)\end{array}$ & $\begin{array}{c}5.6(4.4- \\
25.6)\end{array}$ & 0.79 & $<6,0$ & $<6,0$ \\
\hline
\end{tabular}

Valores expressos em média \pm DP ou mediana e intervalo interquartil. Dados foram processados pela análise de Teste t (paramétricos) e Mann Whitney (não-paramétricos).

Significância foi estabelecida quando $\mathrm{p}<0.05$.

$\mathrm{VR}=$ valor de referência 


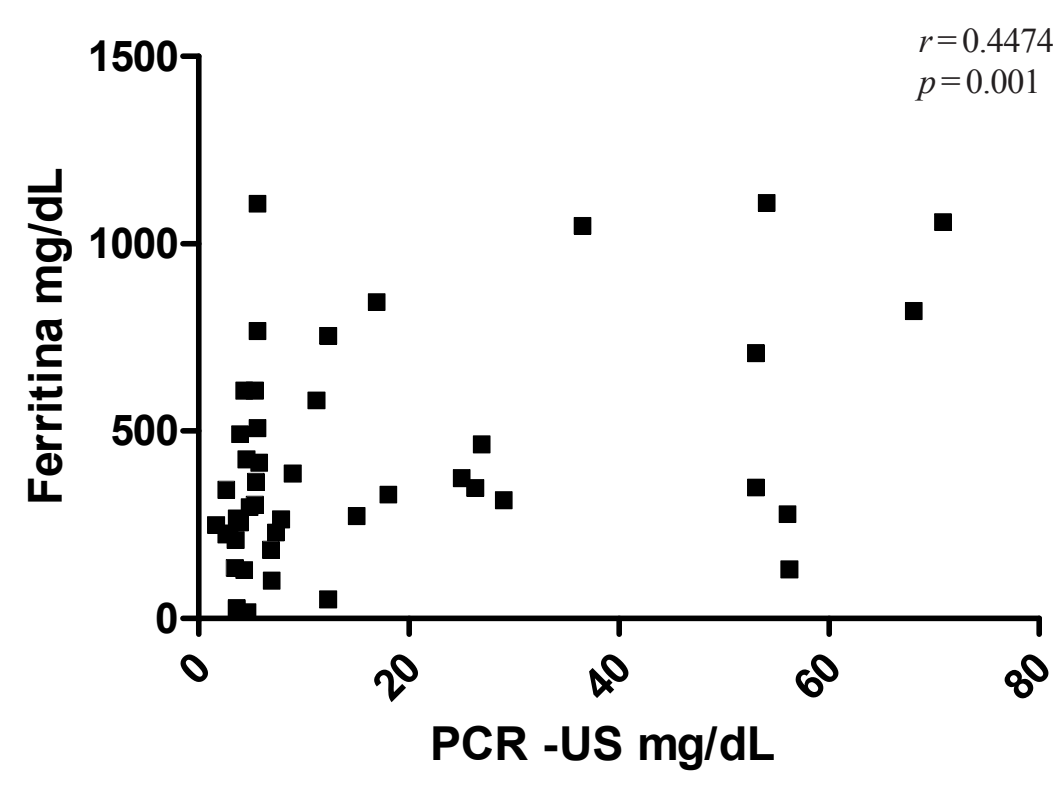

Figura 1. Correlação entre Ferritina e PCR-us na amostra estuda.

Valores expressos em média \pm DP ou mediana e intervalo interquartil. Dados foram processados pela Correlação de Spermann. Significância estabelecida foi $p<0.05$.

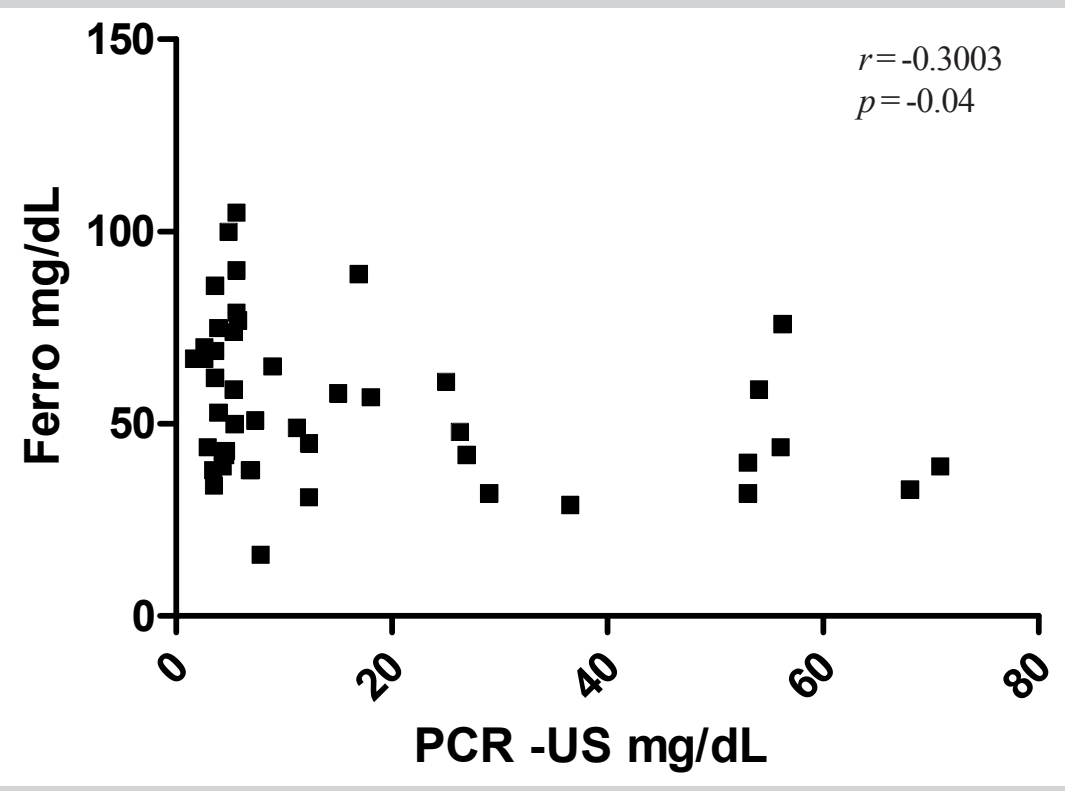

Figura 2. Correlação entre Ferro e PCR-us na amostra estuda.

Valores expressos em média \pm DP ou mediana e intervalo interquartil. Dados foram processados pela Correlação de Spermann. Significância foi estabelecida quando $p<0.05$.

\section{DISCUSSÃO}

No presente estudo avaliou-se as concentrações séricas de marcadores inflamatórios como PCRus e ferritina, biomarcadores renais ureia e creatinina, bem como, dosagens de ferro em 46 pacientes de ambos os sexos com doença renal crônica e submetidos a tratamento hemodialítico.

A hemodiálise muitas vezes desencadeia no paciente um processo inflamatório crônico, que é detectado pelo aumento significativo de marcadores inflamatórios. A inflamação é uma resposta a vários 
estímulos agressivos, como lesão tecidual causada por infecção ou dano físico. A doença renal crônica é considerada uma situação inflamatória que induz a liberação de citocinas pró-inflamatórias. Estas citocinas estão associadas a alterações sistêmicas, induzindo o aumento de proteínas da fase aguda, como a PCR-us e a ferritina. As causas para a resposta inflamatória exacerbada em doentes renais crônicos não estão ainda bem esclarecidas. Existem, no entanto, várias fontes possíveis, incluindo contaminação bacteriana do dialisador, incompatibilidade com a membrana do dialisador e infecção do acesso vascular ${ }^{5}$.

Neste estudo foi observado que no grupo de pacientes pesquisados os valores de PCR-us e ferritina estão acima dos valores de referência. Dados semelhantes foram encontrados em outro estudo ${ }^{8}$, que encontrou em pacientes submetidos à hemodiálise um aumento nas dosagens de PCR-us, mostrando que esta proteína pode ser considerada um importante marcador de estados inflamatórios neste grupo de pacientes. A PCR-us é evidenciada principalmente em estados inflamatórios agudos, no entanto, níveis alterados também podem ser encontrados em estados crônicos. A PCR-us é um marcador muito sensível e importante de inflamação sistêmica e dano tecidual, visto que, sua síntese é predominantemente hepática e começa de 4 a 6 horas após o estímulo 9 .

Uma das principais funções da PCR é o reconhecimento e eliminação, por meio do sistema complemento e fagócitos de patógenos e células danificadas do próprio hospedeiro ${ }^{10,11}$. Seu papel como proteína de fase aguda decorre do fato de estar presente em muitos pontos da via inflamatória. Ela eleva a fagocitose de partículas antigênicas e de microrganismos, ativando a via clássica do complemento. A PCR liga-se ao componente $\mathrm{Cl}$ do sistema complemento e ativa a C3-convertase, intensificando a fagocitose pela via dos macrófagos. Outra função seria a ligação e ativação seletiva das células T citotóxicas ${ }^{12}$.

Um estudo anterior ${ }^{5}$ encontrou valores aumentados de ferritina em pacientes submetidos em hemodiálise. Resultados tem demonstrado, relação positiva entre o aumento de ferritina com o processo inflamatório de pacientes em hemodiális ${ }^{13}$. Quanto maior o componente inflamatório da doença do paciente, menor será a concentração de transferrina e a capacidade ferropéxica e maior será a ferritina. Níveis elevados de ferritina podem ocorrer associados com processo inflamatório ou infeccioso, apenas como manifestação de fase aguda de inflamação, e não como expressão das reservas de ferro ${ }^{6}$.

Nos últimos anos a inflamação desempenha um papel importante na doença renal crônica, principalmente aos que estão sob terapêutica substitutiva de função renal. A inflamação associa-se a deterioração da função renal sugerindo a inflamação como um fator de risco da progressão da doença ${ }^{14}$.

Esse estado inflamatório crônico nos pacientes em hemodiálise pode ser atribuído a constante ativação dos monócitos e neutrófilos circulantes durante a passagem do sangue no circuito de diálise, transferência de endotoxinas da membrana do capilar de diálise para o sangue durante as sessões, ativação de citocinas inflamatórias e pró-inflamatórias e, principalmente, alterações endoteliais. Células endoteliais são ativadas com expressão de moléculas de adesão celular que se ligam aos leucócitos e migram para os tecidos inflamados ${ }^{15}$.

Estudos evidenciam uma queda nas concentrações de ferro em ambos os sexos. Resultados semelhantes já foram encontrados e demonstraram que o processo inflamatório pode ter um impacto no metabolismo do ferro, alternando a absorção e a mobilização do ferro do sistema reticuloendotelial, de que resulta uma diminuição da disponibilidade de ferro para a eritropoiese, inibindo a proliferação e diferenciação das células eritróides ${ }^{5}$, esses dados corroboram com os resultados encontrados neste trabalho que evidenciam uma correlação negativa entre a PCR-us e os níveis de ferro, como podemos observar na figura 2 ( $p=-0.04$ e $r=-0.3003)$, evidenciando que com o aumento do processo inflamatório de pacientes em hemodiálise teriam uma menor biodisponibilidade de ferro, sugerindo um déficit funcional em ferro. A ativação da cascata das citocinas e a resposta de fase aguda associada induzem alteração do metabolismo do ferro, com retenção deste a nível do sistema retículoendotelial e menor disponibilização para a eritropoiese, contribuindo para o surgimento de anemia ${ }^{14}$.

No processo inflamatório os níveis de ferritina aumentam devido esta proteína ter a capacidade de agregar átomos de ferro, apartando-os para o compartimento de armazenamento do ferro, o que diminuiria a disponibilidade de ferro no processo inflamatório, fato este que contribuiria para uma menor disponibilidade de ferro livre para bactérias e outros microrganismos, otimizando os sistemas bacterios-táticos e bactericidas do soro ${ }^{16}$.

Conforme podemos observar na Tabela 1 , ambos os sexos tiveram um aumento nas dosagens de ureia e creatinina. As dosagens de ureia e creatinina são importantes parâmetros no diagnostico e acompanhamento no tratamento da doença renal crônica. A ureia é um dos produtos finais do metabolismo de proteínas, quando não eliminada de forma correta ocorre um acúmulo na corrente sanguínea na doença renal crônica, causando quadros de uremia e consequentemente aumenta à medida da taxa de filtração glomerular ${ }^{5}$. Os valores de ureia encontrados tanto para homens quanto para mulheres perfizeram a média de 
$177 \pm 75 \mathrm{mg} / \mathrm{dL}$, enquanto que a média da concentração sérica de creatinina foi de $8.6 \pm 3.2 \mathrm{mg} / \mathrm{dL}$, para ambos os sexos. Esses achados condizem com outro estudo já publicado realizado no Rio Grande do Sul, em que pacientes de ambos os sexos submetidos à hemodiálise mostraram valores significativamente aumentados nas dosagens séricos de ureia e creatinina ${ }^{17}$. Desse modo, pode-se perceber, que paralelamente à lesão renal se observa um aumento conjunto das concentrações séricas de ureia e creatinina, sendo estes imprescindíveis para o diagnóstico e monitoramento de pacientes com problemas renais.

\section{CONCLUSÃO}

Observamos no presente estudo que em pacientes com doença renal crônica há um aumento significativo de proteínas de fase aguda da inflamação PCR-us e ferritina e déficit funcional do ferro o que pode contribuir para o desenvolvimento de anemais neste grupo de pacientes.

Desse modo sugere-se que a avaliação periódica das concentrações de PCR-us, ferritina e ferro em pacientes com doença renal crônica submetidos à hemodiálise tem grande importância clínica, para a monitorização e acompanhamento desse grupo de pacientes.

\section{AGRADECIMENTOS}

Os autores agradecem a Universidade do Oeste de Santa Catarina - Campus de São Miguel do Oeste e a Clínica Renal do Extremo Oeste de Santa Catarina pelo apoio na realização deste estudo.

\section{REFERÊNCIAS}

1. Resende M, Santos FA, Souza MM, Thatianna PM. Atendimento psicológico a pacientes com insuficiência renal crônica: em busca de ajustamento psicológico. Revista Brasileira de Psicologia Clínica. 2007; 19 (2): 87-99.

2. Sociedade Brasileira de Nefrologia. Censo de Diálise SBN 2012. Disponível em < http://www.sbn.org.br/pdf/publico2012.pdf> Acesso em: 29 mar. 2015

3. Rennke HG, Dennker BM. Fisiopatologia renal: princípios básicos. 2 ed. São Paulo: Livraria Médica Paulista Editora; 2009.

4. Vieira IRCS. Adesão à Dietoterapia em Doentes Renais Crônicos em Hemodiálise. Tese (Doutorado), Coimbra, Universidade de Coimbra, Faculdade de Medicina, 2009, 201p.

5. Coimbra JLM. Resistência a terapêutica com eritropoietina humana recombinante e níveis plasmáticos de BMP 2 em doentes hemodialisados. Dissertação (Mestrado), Coimbra, Universidade Católica Portuguesa, 2011. 62p.

6. Santos CAL. $O$ padrão inflamatório e anemia em hemodiálise. Tese (Doutorado), Universidade Católica do Rio Grande do Sul, Porto Alegre, 2004, 108p.

7. Neto NSR, Carvalho JF. O uso de provas de atividade inflamatória em reumatologia. Rev. Bras. Reumatol. 2009; 49 (4): 413-430.

8. STEIN V. Avaliação DE Biomarcadores renais e Proteína C Reativa de pacientes com doença renal na pré e póshemodiálise. Trabalho de Conclusão de Curso, São Miguel do Oeste, Universidade do Oeste de Santa Catarina, 2014, 43p.

9. MITAKA, C. Clinical laboratory differentiation of infectious versus non-infectious systemic inflammatory response syndrome. Journal Clinica Chimica Acta-Elsevier. 2005; 351 (1-2): 17-29.

10. Wood SP, Thompson D, Pepys MB. The psysiological structure of human C- reactive proteins an its complex with phosphocoline. Journal Structure. 2009; 7 (2): 169-77.

11. Du Clos TW. Fuction of $\mathrm{C}-$ reactive protein. Annals of Medicine. 2000; 32 (4): 274-278
12. Ridker RM, Hennekenens C, Burning J, Rifai NC. C reactive Protein and Other Markers of Inflammation in the Prediction of Cardivascular Diseasein Women. New England Journal of Medicine. 2000; 342: 836-843.

13. Figueiredo MS. Impacto da inflamação na regulação do ferro e deficiência funcional de ferro. Revista Brasileira de Hematologia e Hemoterapia. 2010; 2 (32): 18-21.

14. Neves PL. Inflamação na doença renal crónica. Tese (Doutorado), Lisboa, Faculdade de Medicina de Lisboa, 2004, 326p.

15. Alves CMP, Teixeira MCB, Martino MC. Dosagem de marcadores de lesão endotelial em pacientes com doença renal crônica em hemodiálise. J Bras Patol Med Lab. 2010; 3 (46): 207-213.

16. Monteiro JP, Cunha DF, Da Cunha SFC, Santos VM, Vergara MLS, Correia D. Resposta de fase aguda, subnutrição e estado nutricional do ferro em adultos com AIDS. Revista da Sociedade Brasileira de Medicina Tropical. 2010; 2 (33): 175-180.

17. Bueno CS. Anemia na doença renal crônica em hospital da região noroeste do estado do Rio Grande do Sul. Trabalho de Conclusão de Curso, ljuí, Universidade Regional do Noroeste do Estado do Rio Grande do Sul, 2013, 32p.

\section{Correspondência}

Eduardo Ottobelli Chielle

Rua Oiapoc, 211, Bairro Agostini

São Miguel do Oeste - Santa Catarina - Brasil

CEP: 89.900-000

Tel.: (49) 36311072

E-mail: eduardochielle@yahoo.com.br 